\title{
Neuroinflammation and the $A P O \varepsilon$ genotype: Implications for Alzheimer's disease and modulation by dietary flavonoids and n-3 polyunsaturated fatty acids
}

\author{
David Vauzour* and Anne Marie Minihane \\ Department of Nutrition, Norwich Medical School, University of East Anglia, Norwich, UK
}

\begin{abstract}
Alzheimer's disease (AD) is the most common type of dementia with its pathology considered to be the result of complex interactions between genetic and environmental factors. Amongst a large variety of genes analysed, the APO epsilon genotype, represents the only firmly established common genetic risk factor for dementia, with the APOE4 carriers being at 3-16 fold increased risk of AD. Although, the mechanisms by which $A P O \varepsilon$ genotype impacts on $\mathrm{AD}$ progression are not fully understood, recent evidence suggests that a large component of the increased risk associated with an APOع4 genotype is likely to be due to increased neuroinflammation and the subsequent loss of cognitive functions. There is increasing evidence from human epidemiological and rodent studies that the consumption of flavonoid-rich foods and $n-3$ polyunsaturated fatty acids can beneficially influence normal cognitive function. Investigation of the underlying physiological and molecular mechanisms indicates a positive impact of these dietary components on neurogenesis and neuroinflammation. This review will summarise the evidence of the impact and mechanisms underlying the impact of APOE genotype on dementia and AD and the potential role of dietary flavonoids and n-3 polyunsaturated fatty in modulating neuroinflammation and neurocognitive performances. Examination of molecular targets is suggestive that increased intakes of these dietary components have the potential alone or in an additive fashion to ameliorate the pathological consequences of the APO\&4 allele. However research examining the ability of dietary strategies in this large population genotype subgroup is distinctly lacking.
\end{abstract}

Keywords: Neuroinflammation, apolipoprotein E, flavonoids, Alzheimer's disease, n-3 polyunsaturated fatty acids

\section{Introduction}

Alzheimer's disease (AD) is the most common type of dementia and a significant cause of disability

*Corresponding author: David Vauzour, Norwich Medical School, Faculty of Medicine and Health Sciences, University of East Anglia, Norwich NR4 7TJ, UK. Tel.: +44 1603 591732; Fax: +44 1603 593752; E-mail: d.vauzour@uea.ac.uk. in the elderly. In the latest World Alzheimer Report, Alzheimer's disease International estimated that there are 35.6 million people (2010) worldwide living with dementia which is predicted to increase to 65.7 million by 2030 and 115.4 million by 2050 . AD is characterised by a progressive impairment of memory and other cognitive skills leading to dementia. The major pathogenic factors associated with AD include extracellular accumulation of amyloid-beta peptide 
$(\mathrm{A} \beta)$ oligomers, intracellular aggregates of the protein Tau, and the loss of cholinergic forebrain innervation. Neuroinflammation is being increasingly recognised for its overall role in AD pathology including the acceleration of neuronal loss and protein deposition. In most cases, neuroinflammation constitutes a beneficial process involved in the maintenance of organ homeostasis and brain resolution in response to infection or injury [1]. However, sustained neuroinflammatory processes may contribute to the cascade of events leading to the progressive neuronal damage observed in $\mathrm{AD}$ [2].

The life long risk of developing $\mathrm{AD}$ and age of onset has a large genetic component. Amongst a large variety of potential genetic targets, the apolipoprotein epsilon genotype $(A P O \varepsilon)$ represents the only firmly established common genetic risk factor for dementia. APOE 4 carriers are at 3-16 fold increased risk of $\mathrm{AD}$ with a $10 \mathrm{y}$ earlier age of onset $[3,4]$. The 'importance' of the $A P O \varepsilon 4$ as an AD risk factor is highlighted by the fact that $>60 \%$ of $\mathrm{AD}$ patients are carriers of the APO\&4 allele even though it is only present in approximately $25 \%$ of general Caucasian populations. The mechanisms by which APOE genotype impacts on $\mathrm{AD}$ pathophysiology is not fully understood but its relatively moderate effect on the plasma lipid profile is unlikely to be the sole explanation for the genotype-mediated increases in disease risk. Recently, the immuno-modulatory and inflammation modulatory properties of the apoE protein have been recognised and shown to be altered in an isoform dependent manner. Such findings may help to explain the significantly increased $\mathrm{AD}$ risk in $A P O \varepsilon 4$ carriers.

Human epidemiological evidence, randomised controlled trials (RCTs) and cell and animal studies indicate that physiological concentrations of dietary flavonoids and long chain n-3 polyunsaturated fatty acids (LC n-3 PUFA) are able to exert neuroprotective actions, through their interactions with critical neuronal/glial intracellular signaling pathways pivotal in controlling neuronal resistance to neurotoxins (including oxidants ("indirect" antioxidant nature) and inflammatory mediators), and subsequent impact on neuronal differentiation, long-term potentiation and memory [5-8].

The aim of this review is to summarise the existing evidence on the APOع4-AD associations and on the beneficial effects of flavonoids and n-3 polyunsaturated fatty acids on neurocognitive performances in humans and rodent models. A particular focus will be the impact of $A P O \varepsilon$ genotype and flavonoids/LC n-3 PUFA on neuroinflammation and cell signalling pathways, with identified molecular targets strongly suggesting that these dietary components may be effective at counteracting the pathological consequence of the $A P O \varepsilon 4$ allele.

\section{Neuroinflammation as a hallmark of Alzheimer's disease pathology}

Emerging evidence is demonstrating the central role of neuroinflammation in 'healthy brain ageing' and risk of dementia and $\mathrm{AD}[9,10]$. Neuroinflammation is 'driven' by activated resident glial cells (astrocytes and microglia) which result in invasion of circulating immune cells and the production of pro-inflammatory, cytokines (TNF- $\alpha$, IL-1 $\beta$, IL-6), nitric oxide (NO), prostaglandin E2, chemokines, and reactive oxygen species (ROS). Several findings support the role of neuroinflammation in the pathogenesis of $\mathrm{AD}$. In post-mortem brain tissues from AD patients, activated microglial cells surrounding amyloid- $\beta$ plaques $(A \beta$ or senile plaque, one of the defining pathological features of $\mathrm{AD}$ ) and increased levels of cytokines have been reported [11]. Long term use of non-steroidal anti-inflammatory drugs (NSAIDs) have been shown to lower the risk of $\mathrm{AD}$ in later life [12]. Furthermore, gene variants of several inflammatory cytokines and their receptors [13] have been shown to modulate $\mathrm{AD}$ risk and studies with transgenic animal models of $\mathrm{AD}$ demonstrate that inflammation is a key component of $\mathrm{AD}$ pathogenesis. Markers of inflammation in microglia and astrocytes are significantly increased in the hippocampus of both aged animals and humans $[14,15]$. For example, microglial cells isolated from aged mice's brains have increased basal levels of proinflammatory cytokines, which could exacerbate cognitive deficits associated with neuroinflammation [16].

A potential mechanism by which neuroinflammation may hinder memory during normal or pathological aging is believed to be linked to alterations in neurogenesis. In support of this statement, it has recently been suggested that pro-inflammatory cytokines may contribute to the anti-neurogenic effect by suppressing hippocampal neurogenesis in the aging brain $[15,17]$. The reasons for decreased neurogenesis with aging may be related to an intrinsic inability to respond to the proliferative stimulation in the neurogenic niche, a reduction of proliferative stem cells number, activated microglia and neuroinflammation [18]. 
Although substantial evidence suggests that chronic inflammation in the CNS may contribute to neuronal dysfunction and loss, the exact molecular mechanisms involved in inflammatory-induced neuronal death and overall $\mathrm{AD}$ pathology remain unclear. Emerging evidence suggests that regulation of signal transduction pathways, such as the mitogen activated protein kinase (MAPK) signalling pathway, play an important role in activated glial-induced neuronal death. MAP kinases, which include extracellular signal-regulated kinase (ERK1/2), c-Jun N-terminal kinase (JNK1/2/3), and p38 kinase $(\mathrm{p} 38 \alpha / \beta / \gamma / \delta)$, are important in the transduction of extracellular signals into cellular responses. When activated, these kinases phosphorylate both cytosolic and nuclear target proteins resulting in the activation of transcription factors and ultimately the regulation of gene expression [19]. Both p38 and JNK have been reported to mediate activated gliainduced neuronal death [20,21]. MAPK signalling has been shown to regulate the activation of iNOS and subsequent $\mathrm{NO}^{\bullet}$ production and cytokine release in glial cells. Downstream of the MAP kinase signalling activation in glial cells, various transcription factors including the nuclear transcription factor $\kappa \mathrm{B}(\mathrm{NF}-\kappa \mathrm{B})$, the activator protein-1 (AP-1) and the signal transducer and activator of transcription-1 (STAT-1) have been shown to be involved in pro-inflammatory responses in astrocytes and microglia [22-29]. Of these transcription factors, NF- $\mathrm{KB}$ can be activated by a wide range of oxidative and pro-inflammatory stimuli and is mainly controlled by elements of the MAPK signalling pathways that are activated during neuroinflammation. For example, ERK has little effect on NF-кB activation or iNOS induction in astrocytes [30, 31], whilst p38 and JNK promote NF-кB and iNOS activation in both astrocytes and microglia $[32,33]$. NF- $\mathrm{B}$ activation is observed in a number of neurodegenerative disorders. For example, in studies of post-mortem $\mathrm{AD}$ patients, neurons and astrocytes in the vicinity of $\beta$-amyloid plaques show increased NF- $\mathrm{B}$ immunoreactivity [34]. Upon activation, NF- $\mathrm{B}$ influences the expression of a complex array of genes which serve important functions in cellular responses to injury and in neuronal plasticity. Amongst these genes, several injury-responsive cytokines, including TNF- $\alpha$ and IL-6, are produced in particularly high amounts by microglia and astrocytes [35]. Interestingly, although enhanced NF- $\mathrm{KB}$ activity is strongly associated with neurodegeneration, its activity is essential for astrocyte and microglial survival $[36,37]$.

\section{3. $A P O E$ genotype in neuroinflammation and cognitive decline}

Amongst a large variety of gene variants analysed, the $A P O \varepsilon$ genotype is the most significant common genetic determinant of risk, age of onset, clinical outcome and rate of progression of a number of neurodegenerative diseases including $\mathrm{AD}[38,39]$. The $A P O \varepsilon$ gene is highly polymorphic, with the epsilon non-synonymous variant yielding three common apoE isoforms, the apoE2 (Cys 112 Cys 158), apoE3 (Cys 112 Arg 158), and apoE4 (Arg 112 Arg 158) mature proteins [40]. Approximately 55-60\% of Caucasians are homozygous for the $\varepsilon 3$ allele ( $\varepsilon 3 / \varepsilon 3)$, with $12-15 \%$ being $\varepsilon 2$ carriers $(\varepsilon 2 / \varepsilon 2, \varepsilon 2 / \varepsilon 3)$ and the remaining $25-27 \%$ being either heterozygous or homozygous for the APO 4 isoform $(\varepsilon 3 / \varepsilon 4, \varepsilon 4 / \varepsilon 4)$ [41]. Based on replication in a large number of human association studies, predominately using a candidate gene approach and over the last 5 years, genome wide analysis studies (GWAS), have firmly established the $\varepsilon 4$ allele of $A P O \varepsilon$ as a susceptibility factor for AD [42]. Output from the AlzGene database (www.alzgene.org), which includes data from 1395 independent studies, exemplifies the highly clinical significant impact of $A P O \varepsilon$ genotype on AD risk, with relative risks (RR) of 3 and $12-15$ in $A P O \varepsilon 3 / \varepsilon 4$ and $A P O \varepsilon 4 / \varepsilon 4$ individuals relative to the wild-type $A P O \varepsilon 3 / \varepsilon 3$ genotype [3]. The importance of $A P O \varepsilon$ genotype in cognitive health is further evidenced by the fact that $>60 \%$ of AD sufferers are APOE 4 carriers relative to $25-27 \%$ in the general population. Furthermore in healthy aging populations an $A P O \varepsilon 4$ genotype is associated with poorer cognitive performance [43], a more rapid decline in cognitive function [44], higher conversion rates of mild cognitive impairment (MCI) to AD [45], and an earlier age of $\mathrm{AD}$ onset [38]. For example, in "The Cache County Study", carriers of the APOE4 allele in the elderly participants (mean age $74 \mathrm{y}$ ) had lower baseline cognition and steeper decline in cognition than non-carriers over the $7 \mathrm{y}$ follow up period [44]. These results were further substantiated by another longitudinal study, demonstrating that $A P O \varepsilon 4$ status had a significant impact on cognitive and functional decline on multiple measures, including working memory [45]. Animal studies also suggest a strong role of $A P O \varepsilon$ genotype in learning and memory $[46,47]$ with spatial memory being particularly affected in $A P O \varepsilon 4$ transgenic mice, [48].

As the name suggest apoE was originally described as an important modulator of circulating lipoprotein 
metabolism. The observed modestly higher plasma LDL-cholesterol concentrations (which are thought to in part explain the increase in cardiovascular disease risk reported in those with an $A P O \varepsilon 4$ genotype) in $A P O \varepsilon 4$ carriers may also contribute to the increased risk of $\mathrm{AD}$. [49, 50]. However emerging evidence is suggestive that a dysregulation of the brain response of activated glial inflammation and oxidative sensitive metabolic pathways in $A P O \varepsilon 4$ carriers may in part underlie the increased risk of neurodegenerative disorders in this large population subgroup [51]. In support of this statement, a recent prospective study investigating the effects of both APOE genotype and NSAIDs reported a decreased risk in $A P O \varepsilon 4$ carriers, with little to no reduction risks among NSAID-using, nonAPOE4 subjects [52]. These findings further support earlier epidemiologic work by Hayden and collaborators, who also reported a significant $\mathrm{AD}$ protective effect of NSAIDs that was most notable in $\mathrm{APO \varepsilon} 4$ subjects [53]. Such observations have led scientists to investigate the role of $A P O \varepsilon$-mediated neuroinflammation in animal and cell models.

Several studies have repeatedly reported that exogenously applied $A P O \varepsilon 4$ had a higher inflammatory status relative to $A P O \varepsilon 3$ in both astrocytes and microglial cells $[54,55]$. For example, using cells, transgenic human $A P O \varepsilon 3$ and $A P O \varepsilon 4$ mice and human models, studies have reported increased inflammatory cytokine production (i.e. TNF- $\alpha$ and IL-6) [56], reduced levels of the anti-inflammatory HO-1 and IL-10, increased NO production [57, 58], F2-isoprostanes [59], superoxide concentrations and membrane oxidation, associated with the $A P O \varepsilon 4$ allele [60-62]. Such results were subsequently confirmed by analysing the dose-dependent association of the APOE4 allele with innate immune response [63] and cytokine-induced neurotoxicity [64], therefore suggesting that the cognitive deficits and cortical neuropathology associated with the $A P O \varepsilon 4$ allele may be partly due to an impact of genotype on inflammatory mechanisms and subsequent neurogenesis inhibition (Fig. 1).

The loss of neurons associated with neuroinflammation and brain atrophy, occurs when there is an imbalance between, neuronal apoptosis and loss of dendrite density, and neuronal repair and neurogenesis $[15,17,18]$. Using transgenic knock-in mice and human post-mortem brain tissue, human $A P O \varepsilon 3$ and wild-type mice had a higher density of dendritic spines than human $A P O \varepsilon 4$ and $A P O \varepsilon$ knock-out mice in the 1 and 2 year age group, while at 3 weeks there were no differences between the groups. Significantly in human brain, $A P O \varepsilon 4$ dose correlated inversely with

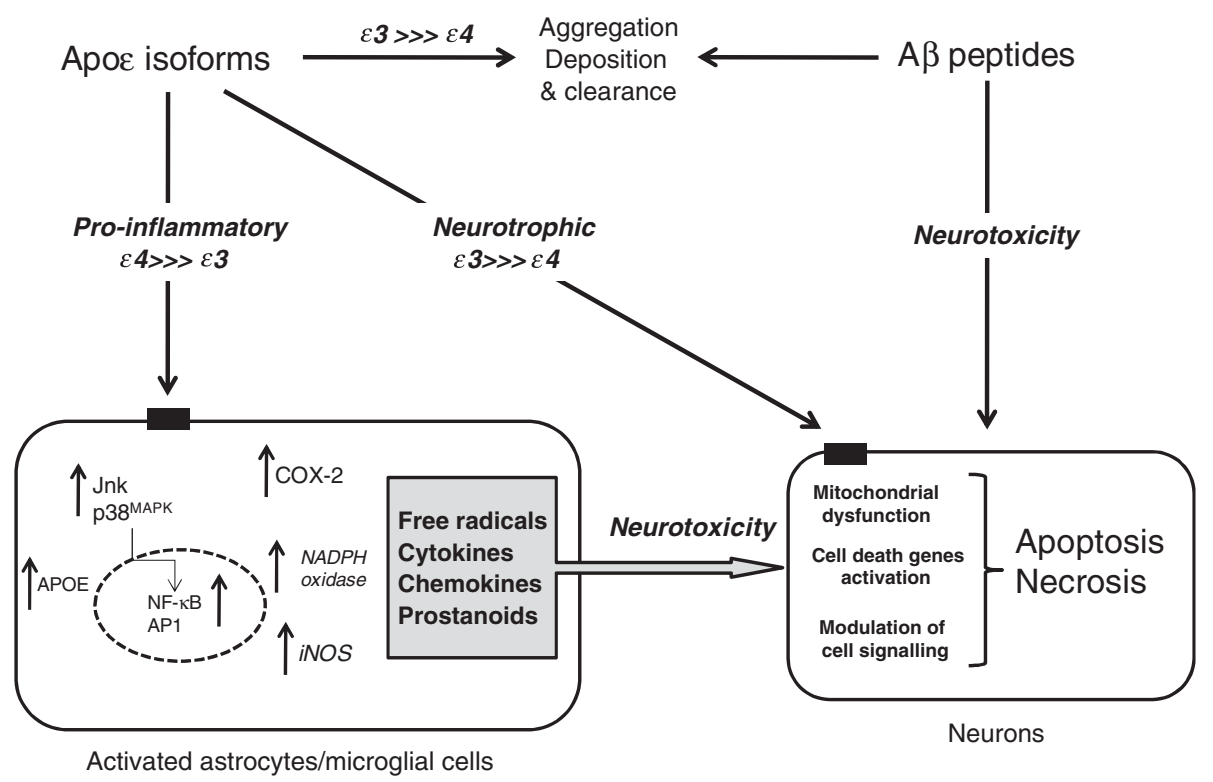

Fig. 1. ApoE-mediated neuroinflammation and neuronal death. Relative to $A P O \varepsilon 4, A P O \varepsilon 3$ is thought to have a neuroprotective role through its neurotrophic actions (stimulation of neurite outgrowth) and suppression of A $\beta$-induced neurotoxicity. On the other hand, $A P O \varepsilon 4$ may result in stimulation of pro-inflammatory molecules (e.g. IL-1 $\beta, \mathrm{TNF}-\alpha$ ), increase in reactive oxygen and nitrogen species (NO, superoxide, peroxynitrite) and activate cell death genes and signaling pathways, leading ultimately to neuronal death. 
dendritic spine density of neuronal cell in the hippocampus of both $\mathrm{AD}$ and aged normal controls [65]. Such differences may arise from the fact that neurons developing in $A P O \varepsilon 4$ carriers display a mild delay in neuronal maturation, reflected by impairment in dendritic length and complexity, increased membrane resistance and diminished GABAergic interneurons and synapses [66].

The ability of $A P O \varepsilon 4$ to promote such disparity has been proposed to be the result of its differential activity (compared to $A P O \varepsilon 2$ and $A P O \varepsilon 3$ ) towards glial and neuronal signaling. ApoE has been reported to modulate various signalling pathways in an isoform-specific manner. Indeed, apoE isoforms differentially influence calcium channels causing altered increases in free intracellular calcium [67]. Moreover, apoE isoforms were also observed to affect PKCalpha translocation [68] and to modulate the glycogen synthase kinase- $3 \beta$ (GSK-3 $\beta$ ), the protein kinase B (Akt) [69], the extracellular signal-regulated kinase 1/2 (ERK), c-jun N-terminal kinase 1/2 (JNK) [70] and the transcriptional activity of the cAMP response element-binding protein (CREB) [71]. More recently, Ophir and colleagues demonstrated that the genes that were most differentially expressed in $A P O \varepsilon 4$ compared to $A P O \varepsilon 3$ were significantly enriched in nuclear factor $\kappa \mathrm{B}(\mathrm{NF} \kappa \mathrm{B})$ response element [72]. On the other hand, other studies supported the hypothesis that $A P O \varepsilon$ genotype-mediated effects in microglia were p38 dependent [64, 73]. The link between $A P O \varepsilon$, signaling and inflammatory outcomes is intriguing, although further work is required to fully understand the molecular mechanisms underlying the differential effects of $A P O \varepsilon$ in neurological disorders (Fig. 1).

\section{Diet, neuroinflammation and cognitive function}

The majority of existing drug treatments for $\mathrm{AD}$ such as cholinesterase inhibitors and NMDA receptor antagonists do not target the underlying degeneration of neurons, and consequently there is a great need to develop alternative therapies capable of preventing the progressive loss of specific neuronal populations [74, 75]. Various therapeutic approaches that directly or indirectly influence inflammatory responses have/are being developed and tested (see review by Glass et al.
[1]). Recently, much interest has focused on the suggested anti-inflammatory and neuroprotective effects of dietary derived flavonoids and the LC n-3 PUFA, eicosapentaenoic acid (EPA) and docosahexaenoic acid (DHA), rendering these molecules as potential candidates for use in preventative and therapeutic strategies to reduce the risk of chronic degenerative diseases development, including AD. The following sections will review the role of flavonoids and n-3 polyunsaturated fatty acids in preventing neuroinflammation and modulating age-related memory decline, and will describe the potential mechanisms of action underlying their neuroprotective effects.

\subsection{Dietary flavonoids, neuroinflammation and cognitive functions}

Dietary intervention studies with flavonoid-rich plant extracts in several mammalian species including humans, have indicated an ability of these dietary components to influence the incidence and onset of neurodegeneration and to counteract age-related cognitive decline [76-80]. Interventions with Camellia sinensis (tea) [81-85], Gingko Biloba [86, 87], Theobroma cacao (cocoa) [88-90] and Vaccinium spp (blueberry) [91-94], have demonstrated beneficial effects on memory and learning in both animals and humans. For example, the Ginkgo biloba extract EGb761 has been shown to protect rat primary hippocampal neurons against nitric oxide induced damage [95] and to decrease beta-amyloid-induced neurotoxicity in a neuroblastoma cell line stably expressing an AD-associated mutation [96]. Furthermore, green tea catechins improved both reference and working memory, and decreased hippocampal reactive oxygen species in rats [82]. The plant-derived flavanol, (-)-epicatechin, was observed to improve spatial memory retention and to increase angiogenesis and neuronal spine density in the gyrus dentate of treated mice [97]. Interestingly, CNS imaging studies in humans have demonstrated that the consumption of cocoa flavanols (900 mg flavanols daily for 1 week), may enhance cortical blood flow as assessed by transcranial Doppler ultrasound and gadolinium perfusion magnetic resonance imaging [88]. Increased cerebrovascular function, especially in the hippocampus, a brain region important for memory, may facilitate adult neurogenesis. Upon microarray analysis of hippocampal tissue of mice that consumed this compound, 
expression of genes associated with neurite extension and synaptic plasticity was enhanced [98].

In vitro mechanistic investigations have started to elucidate the molecular mechanisms by which flavonoids and their metabolites may mediate such behavioural changes. Emanating results suggest that flavonoids, at dietary relevant concentrations, induce neuronal effects by modulating intracellular signalling cascades which are pivotal in sensing, interpreting and ultimately determining the fate of a cell following a toxic insult $[5,6,99-101]$. For example, green tea catechins [102, 103] and blueberry [92, 104-106] have been proposed to prevent age-related deficits in memory and learning through their actions on receptors, kinases and transcription factors known to be key in defining hippocampal plasticity and neurogenesis [107]. Furthermore, the enhancement of spatial memory by blueberry flavonoids was paralleled by alterations in signalling pathways known to be involved in long-term potentiation (LTP) and synaptic plasticity the hippocampus [93].

Since evidence emerged that non-steroidal antiinflammatory drugs may be effective in delaying the onset of neurodegenerative disorders [108], there has been much interest in the development of new drugs capable of preventing neuroinflammatory mediated brain injury. Although rather complex, the main anti-inflammatory properties of flavonoids include inhibition of NO production, and inhibition of expression of inflammatory cytokines (e.g. TNF- $\alpha$, IL-1 $\beta$ and MCP-1) and adhesion molecules (e.g. VCAM-I, ICAM-1 and E-selectin) [109, 110]. For example, the citrus flavanone naringenin has recently been found to be highly effective in reducing LPS/IFN- $\gamma$-induced glial cell activation and resulting neuronal injury, via an inhibition of p38 and STAT-1, and a reduction in iNOS expression [111]. Flavonoids present in blueberry have also been shown to inhibit NO, IL-1 $\beta$ and TNF- $\alpha$ production in activated microglia cells [112], whilst the flavonol quercetin [113], the flavones wogonin and bacalein from Scutellaria baicalensis [114], and the flavanols catechin and epigallocatechin gallate (EGCG) [115] have all been shown to attenuate microglia and/or astrocyte mediated neuroinflammation. Their ability to exert such actions, again appear to rely on their ability to directly modulate protein and lipid kinase signalling pathways [6, 99, 116], pro-inflammatory transcription factors [117] and the downstream regulation of iNOS and cyclooxygenase (COX-2) expression, NO production, cytokine release and NADPH oxidase activation. For example, the flavonol fisetin, a natural chemical found in strawberries, has been shown to inhibit p38 MAP kinase phosphorylation in LPS-stimulated BV-2 microglial cells [118] and the flavone luteolin found in high concentrations in celery and green pepper, inhibits IL-6 production in activated microglia via inhibition of the JNK signalling pathway [24]. Additional mechanisms have been also suggested for the ability of flavonoids to delay the initiation of and/or slow the progression of AD-like pathology, including a potential to inhibit neuronal apoptosis triggered by neurotoxic species (e.g. oxidative stress and neuroinflammation) or to disrupt amyloid $\beta$ aggregation and to affect the amyloid precursor protein processing through the inhibition of $\beta$-secretase (BACE-1) and/or activation of $\alpha$-secretase (ADAM10) (See review by Williams et al. [119]) (Fig. 2).

A limited body of evidence is suggestive that $A P O \varepsilon$ genotype may influence the beneficial effect of flavonoids in relation to dementia and AD. For example, the frequent consumption of fruits and vegetables was associated with a decreased risk of all cause dementia (hazard ratio [HR] $0.72,95 \%$ CI 0.53 to 0.97 ) especially among non APOE\&4 carriers [120]. Furthermore, in $A P O \varepsilon$ targeted replacement mice, $A P O \varepsilon 3$ mice were more responsive to the TNF-alpha lowering properties of dietary quercetin supplementation as compared to $A P O \varepsilon 4$ animals. Further work is required to gain an understanding of the physiological and molecular responses to altered flavonoid intake according to $A P O \varepsilon$ genotype.

\subsection{Dietary long chain n-3 PUFA, neuroinflammation and cognitive function}

Relative to systemic tissue, the brain is 5-10 fold enriched in DHA, a LC n-3 PUFA found in fish and some marine algae, indicating the essential role of DHA for normal neurological function [121]. In support of this statement, it has been reported that AD patients have significantly lower brain and systemic DHA levels compared to control subjects, with serum cholesteryl ester-DHA levels reported to be progressively reduced with severity of clinical dementia [122]. Numerous prospective epidemiological cohorts such as the Framingham Heart Study (9.1 y follow up) and the SU.VI.MAX Cohort (13 y follow-up) have reported an association between LC n-3 PUFA intake and status, 


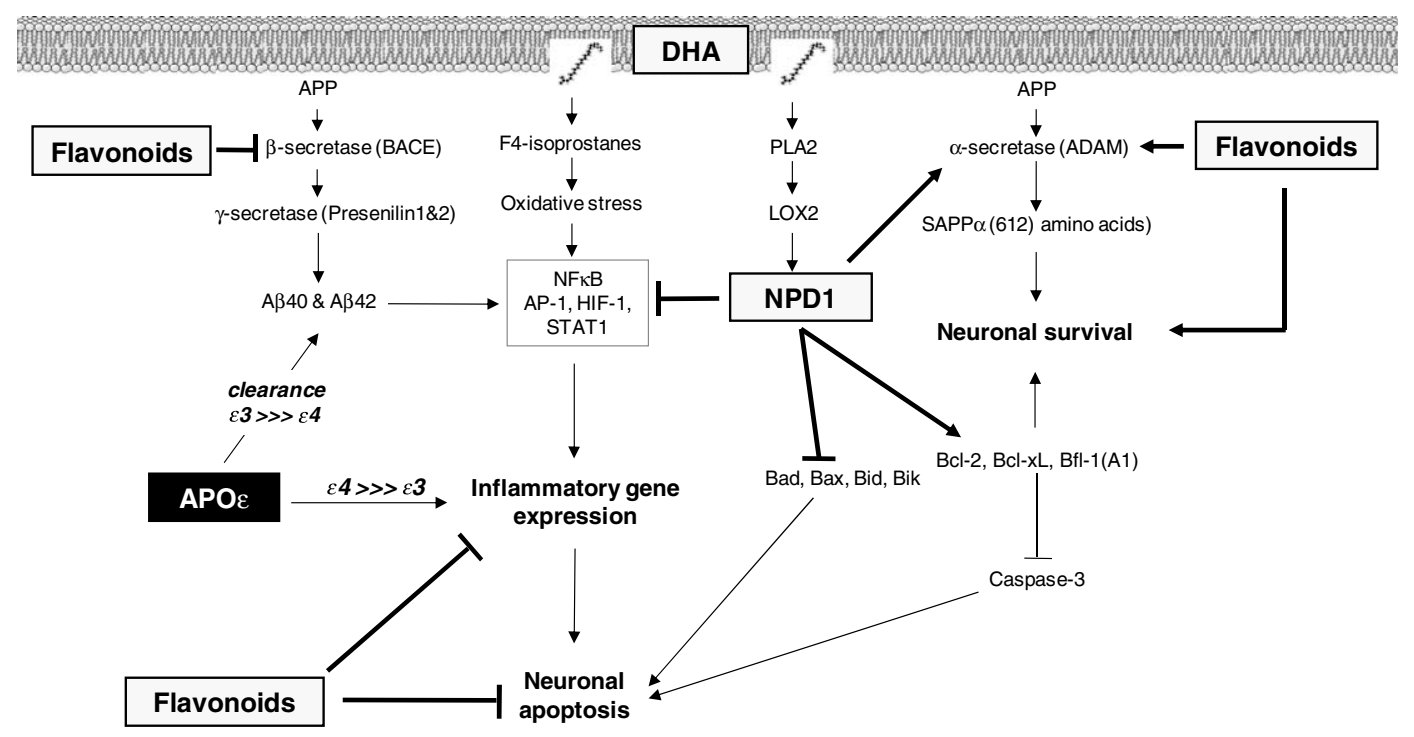

Fig. 2. Impact of flavonoids and DHA derivatives on amyloid precursor protein (APP) metabolism and neuronal survival/apoptosis. Both flavonoids and DHA may delay the initiation of and/or slow the progression of AD-like pathology, including a potential to inhibit neuronal apoptosis triggered by neurotoxic species (e.g. oxidative stress and neuroinflammation) or disrupt amyloid $\beta$ aggregation and effects on APP processing. Whilst, non-enzymatic DHA oxidation produces F4-isoprostane and increases oxidative stress, lipo-oxygenase (LOX)-mediated DHA oxidation generates neuroprotectin D1 (NPD1), a potent anti-inflammatory and anti-apoptotic molecule in the brain.

and cognitive function and AD risk [123, 124]. Less consistent findings have emerged from RCTs, with evidence suggesting little benefits of LC n-3 PUFA supplementation in those with pre-existing $\mathrm{AD}$, but some benefits reported in healthy individuals or those with 'very mild' AD [125, 126]. For example, a previous "omega-3" fatty acid clinical trial in Sweden demonstrated a significant reduction in MMSE decline rate in the LC n-3 PUFA treated group compared with the placebo group in a subgroup of patients with a very mild cognitive dysfunction, observed at 6 and 12 months [125]. Furthermore, a Phase III clinical trial of purified DHA from microalgae has been performed in the US. The MIDAS study reported statistically significant improvements with $900 \mathrm{mg} / \mathrm{d}$ algal DHA over placebo on the Paired Associates Learning (PAL) test, with nearly double the reduction in errors on the test in the DHA group compared to placebo, therefore demonstrating improvements in learning and episodic memory function over 6 months in older adults with age-related cognitive decline [126].

Functional studies in rodent models also support improved LC n-3 PUFA and DHA mediated cognitive function, with post-supplementation improvements in performance in the spatial tasks [127]. Indeed, supplementation with DHA was observed to enhance both neuronal differentiation from G-olig2 embryonic stem cells and to improve spatial learning performance in the Morris water maze compared with control wild type littermates [128]. A reduction in brain DHA levels down to $3-5 \%$ of the total fatty acids was also associated with poor water-maze learning memory performance [129], and recovery of brain DHA levels to $8-12 \%$ of the total fatty acids led to recovery of water maze learning memory [127].

Analysis of hippocampal and other brain tissues derived from rodent and post-mortem humans, along with cell culture studies have indicated numerous overlapping structural and physiological 'benefits' underlying these cognitive effects, including; (i) the provision of DHA for membrane synthesis, (ii) an increased dendritic spine formation, neurite outgrowth and neurogenesis [130], (iii) a reduction in neuroinflammation and inflammatory cytokine production, largely via a down regulation of NF-кB [131]. Mechanisms proposed to explain DHA's anti-inflammatory effects, include activation of Akt, mTOR, and p70S6K signaling $[132,133]$, and conversion into other derivatives such as cyclopentone neuroprostanes [134]. Recent evidence suggests that much of the benefit of DHA on hippocampal (primary brain region 
affected in $\mathrm{AD}$ ) structure and function is likely to be due to neuroprotectin D1 (NPD1), a potent anti-inflammatory lipooxygenase (LOX) DHA oxidation product which inhibits oxidative stress-mediated proinflammatory gene induction and apoptosis in the brain [135]. NPD1 has been observed to inhibit NF- $\kappa \mathrm{B}$ activation and cyclooxygenase-2 (COX-2) expression in brain following ischemia-reperfusion [136], while A $\beta$ peptide-induced apoptosis is associated with ERK and p38-NF-кB-mediated COX-2 up-regulation [137]. Neuroprotection mediated by NPD1 may further involve components of signaling pathways upstream of NF- $\mathrm{BB}$ activation and DNAbinding [138] (Fig. 2).

The presence of the $A P O \varepsilon 4$ allele may modify the relationship of LC n-3 PUFA to dementia and AD. For example, in the Alzheimer's Disease Cooperative Study (ADCS), while there was no DHA treatment effect on any outcome measure in the $A P O \varepsilon 4$-positive group, patient receiving DHA $(2 \mathrm{~g} / \mathrm{d})$ in the $A P O E$ $\varepsilon 4$-negative group had a significantly lower decline in mean change in both ADAS-cog and MMSE scores over 18 months [139]. These results further support previous study findings demonstrating a decreased risk of dementia and Alzheimer disease upon frequent consumption of omega- 3 rich oils, especially amongst APO\&4 non carriers [120, 140, 141]. Such genotypic variations may reside in a differential absorption and transport of PUFAs [140], or to a modification of the effects of fat intake on amyloid beta metabolism [142]. The interaction between dietary fat and APOE genotype on risk for dementia or $\mathrm{AD}$ therefore warrants further investigation.

\subsection{Potential additive effects of dietary flavonoids, and long chain n-3 PUFA, on neuroinflammation and cognitive functions}

LC n-3 PUFA (in particular DHA) deficiency represents a plausible pathoethiological mechanism for neuropathology associated with cognitive aging and dementia [143]. As highlighted in the previous sections, both LC n-3 PUFA and flavonoid treatments have been reported to exert positive effects on a number of putative mechanisms of age-related decline by regulating cellular and molecular targets that lead to a decreased neuroinflammation and ultimately promote neurogenesis and neurite outgrowth. However, although some overlap in activity may be evident, due to their chemical nature, these compounds often act at different cellular levels. For example, DHA (highly lipophilic) uniquely provides the fatty acid 'building blocks' (40\% neuronal membranes) for the new cell membrane synthesis associated with increased the neurogenesis and spine density. On the other hand, flavonoids are strong modulators of the intracellular signalling pathways involved in counteracting agerelated oxidative stress and therefore are likely to reduce the non-specific oxidation of the unsaturated DHA, into a non-active oxidation product (i.e. isoprostanes). Although currently completely unknown, it is speculated that the combined effects of these two dietary components may be more beneficial than either administered in isolation.

\section{Conclusion}

With ageing populations, and the exponential increase in AD risk with age, doubling every 5 years (after the age of 60), a 3-fold rise in population prevalence of $\mathrm{AD}$ by 2050 is predicted. As highlighted in this review, neuroinflammation is emerging as a key pathological element of age-related loss of cognitive function. Amongst the genetic mediators, $A P O \varepsilon$ genotype has been firmly established as a highly clinically significant risk factor for $\mathrm{AD}$, with $60 \%$ of $\mathrm{AD}$ patients being $A P O \varepsilon 4$ carriers. However the mechanisms underlying $A P O \varepsilon 4-A D$ associations are only partly understood with recent evidence indicating that neuroinflammation may be involved. Understanding of the pathophysiological mechanisms of the $A P O \varepsilon 4$ genotype at the molecular levels would greatly contribute to new therapeutic developments. Recently, flavonoids and LC n-3 PUFA have emerged as potential dietary strategies to reduce the population incidence of dementia. However, efficacy in RCT is needed to support the relatively consistent epidemiological and mechanistic evidence. Dietary strategies to counteract the large increased risk in $A P O \varepsilon 4$ carriers are unknown and worthy of investigation. Examination of physiological and molecular targets, as conducted in the current review, is suggestive that flavonoids and LC n-3 PUFA alone or in combination may be effective in counteracting the impact of the APO\&4 allele. In this respect, intervention trials using prospective recruitment of study participants would help to gain a more comprehensive understanding of $A P O \varepsilon$ 
genotype-diet-AD risk associations and to gain a better knowledge of the cellular and molecular mechanisms underpinning such interactions. An effective dietary strategy to delay the onset of disease, in particular in 'high-risk', early-onset $A P O \varepsilon 4$ carriers would contribute significantly to morbidity compression in the elderly and increased healthy life expectancy'. Although quantifying the exact impact on total population prevalence of any preventative strategy is difficult, Sloane and co-authors predict that a delay in disease presentation of $5-7 \mathrm{y}$, would reduce the population incidence by as much as 30-50\% [144]. In an era of move to the part replacement of generic population dietary recommendations with personalised/stratified guidance, it is likely that the identification and provision of targeted dietary advice, which could delay or prevent dementia in the large population subgroup of $A P O \varepsilon 4$ carriers, would be would be of considerable societal and economic benefit.

\section{References}

[1] Glass CK, Saijo K, Winner B, Marchetto MC, Gage FH. Mechanisms underlying inflammation in neurodegeneration. Cell. 2010;140(6):918-34.

[2] McGeer EG, McGeer PL. Inflammatory processes in Alzheimer's disease. Progress in NeuroPsychopharmacology \& Biological Psychiatry. 2003;27(5): 741-9.

[3] Bertram L, McQueen MB, Mullin K, Blacker D, Tanzi RE. Systematic meta-analyses of Alzheimer disease genetic association studies: the AlzGene database. Nat Genet. 2007;39(1):17-23.

[4] Farrer LA, Cupples LA, Haines JL, Hyman B, Kukull WA, Mayeux R, et al. Effects of age, sex, and ethnicity on the association between apolipoprotein E genotype and Alzheimer disease. A meta-analysis. APOE and Alzheimer disease meta analysis consortium. JAMA. 1997;278(16):1349-56.

[5] Vauzour D, Vafeiadou K, Rice-Evans C, Williams RJ, Spencer JP. Activation of pro-survival Akt and ERK1/2 signalling pathways underlie the anti-apoptotic effects of flavanones in cortical neurons. J Neurochem. 2007;103(4):1355-67.

[6] Vauzour D, Vafeiadou K, Rodriguez-Mateos A, Rendeiro C, Spencer JP. The neuroprotective potential of flavonoids: a multiplicity of effects. Genes Nutr. 2008;3(3-4):115-26.

[7] Farooqui AA, Horrocks LA, Farooqui T. Modulation of inflammation in brain: a matter of fat. $\mathrm{J}$ Neurochem. 2007;101(3):577-99.

[8] Oster T, Pillot T. Docosahexaenoic acid and synaptic protection in Alzheimer's disease mice. Biochim Biophys Acta. 2010;1801(8):791-8.

[9] Agostinho P, Cunha RA, Oliveira C. Neuroinflammation, oxidative stress and the pathogenesis of Alzheimer's disease. Curr Pharm Des. 16(25):2766-78.
[10] Pratico D, Trojanowski JQ. Inflammatory hypotheses: novel mechanisms of Alzheimer's neurodegeneration and new therapeutic targets? Neurobiol Aging. 2000;21(3):441-5; discussion 51-3.

[11] Rozemuller AJ, van Gool WA, Eikelenboom P. The neuroinflammatory response in plaques and amyloid angiopathy in Alzheimer's disease: therapeutic implications. Curr Drug Targets CNS Neurol Disord. 2005;4(3):223-33.

[12] Szekely CA, Thorne JE, Zandi PP, Ek M, Messias E, Breitner JC, et al. Nonsteroidal anti-inflammatory drugs for the prevention of Alzheimer's disease: a systematic review. Neuroepidemiology. 2004;23(4):159-69.

[13] Zhang Y, Zhang J, Tian C, Xiao Y, Li X, He C, et al. The $-1082 \mathrm{G} / \mathrm{A}$ polymorphism in IL-10 gene is associated with risk of Alzheimer's disease: a meta-analysis. J Neurol Sci. 303(1-2):133-8.

[14] David JP, Ghozali F, Fallet-Bianco C, Wattez A, Delaine S, Boniface B, et al. Glial reaction in the hippocampal formation is highly correlated with aging in human brain. Neurosci Lett. 1997;235(1-2):53-6.

[15] Kuzumaki N, Ikegami D, Imai S, Narita M, Tamura R, Yajima M, et al. Enhanced IL-1beta production in response to the activation of hippocampal glial cells impairs neurogenesis in aged mice. Synapse. 2010;64(9):721-8.

[16] Sparkman NL, Buchanan JB, Heyen JR, Chen J, Beverly JL, Johnson RW. Interleukin-6 facilitates lipopolysaccharideinduced disruption in working memory and expression of other proinflammatory cytokines in hippocampal neuronal cell layers. J Neurosci. 2006;26(42):10709-16.

[17] Koo JW, Duman RS. IL-1beta is an essential mediator of the antineurogenic and anhedonic effects of stress. Proc Natl Acad Sci U S A. 2008;105(2):751-6.

[18] Russo I, Barlati S, Bosetti F. Effects of neuroinflammation on the regenerative capacity of brain stem cells. J Neurochem. 2011;116(6):947-56.

[19] Chang L, Karin M. Mammalian MAP kinase signalling cascades. Nature. 2001;410(6824):37-40.

[20] Xie Z, Smith CJ, Van Eldik LJ. Activated glia induce neuron death via MAP kinase signaling pathways involving JNK and p38. Glia. 2004;45(2):170-9.

[21] Jeohn GH, Cooper CL, Wilson B, Chang RC, Jang $\mathrm{KJ}$, Kim $\mathrm{HC}$, et al. p38 MAP kinase is involved in lipopolysaccharide-induced dopaminergic neuronal cell death in rat mesencephalic neuron-glia cultures. Ann N Y Acad Sci. 2002;962:332-46.

[22] Bianchi R, Giambanco I, Donato R. S100B/RAGEdependent activation of microglia via NF-kappaB and AP-1 Co-regulation of COX-2 expression by S100B, IL-1beta and TNF-alpha. Neurobiol Aging. 2010;31(4):665-77.

[23] Hsieh HL, Wang HH, Wu CY, Yang CM. Reactive oxygen species-dependent c-Fos/Activator protein 1 induction upregulates heme oxygenase-1 expression by bradykinin in brain astrocytes. Antioxid Redox Signal. 2010;13(12):1829-44.

[24] Jang S, Kelley KW, Johnson RW. Luteolin reduces IL-6 production in microglia by inhibiting JNK phosphorylation and activation of AP-1. Proc Natl Acad Sci U S A. 2008;105(21):7534-9.

[25] Kim JH, Min KJ, Seol W, Jou I, Joe EH. Astrocytes in injury states rapidly produce anti-inflammatory factors and 
attenuate microglial inflammatory responses. J Neurochem. 2010;115(5):1161-71.

[26] Kim MO, Si Q, Zhou JN, Pestell RG, Brosnan CF, Locker J, et al. Interferon-beta activates multiple signaling cascades in primary human microglia. J Neurochem. 2002;81(6):136171.

[27] Lu X, Ma L, Ruan L, Kong Y, Mou H, Zhang Z, et al. Resveratrol differentially modulates inflammatory responses of microglia and astrocytes. J Neuroinflammation. 2010;7:46.

[28] Nguyen VT, Benveniste EN. Involvement of STAT-1 and ets family members in interferon-gamma induction of CD40 transcription in microglia/macrophages. J Biol Chem. 2000;275(31):23674-84.

[29] Waetzig V, Czeloth K, Hidding U, Mielke K, Kanzow M, Brecht S, et al. c-Jun N-terminal kinases (JNKs) mediate proinflammatory actions of microglia. Glia. 2005;50(3):235-46.

[30] Choi K, Ni L, Jonakait GM. Fas ligation and tumor necrosis factor alpha activation of murine astrocytes promote heat shock factor-1 activation and heat shock protein expression leading to chemokine induction and cell survival. J Neurochem. 2011;116(3):438-48.

[31] Marcus JS, Karackattu SL, Fleegal MA, Sumners C. Cytokine-stimulated inducible nitric oxide synthase expression in astroglia: role of Erk mitogen-activated protein kinase and NF-kappaB. Glia. 2003;41(2):152-60.

[32] Fernandes A, Falcao AS, Silva RF, Brito MA, Brites D. MAPKs are key players in mediating cytokine release and cell death induced by unconjugated bilirubin in cultured rat cortical astrocytes. Eur J Neurosci. 2007;25(4):105868.

[33] Saha RN, Jana M, Pahan K. MAPK p38 regulates transcriptional activity of NF-kappaB in primary human astrocytes via acetylation of p65. J Immunol. 2007;179(10):7101-9.

[34] Paris D, Patel N, Quadros A, Linan M, Bakshi P, Ait-Ghezala $\mathrm{G}$, et al. Inhibition of Abeta production by NF-kappaB inhibitors. Neurosci Lett. 2007;415(1):11-6.

[35] Mattson MP, Camandola S. NF-kappaB in neuronal plasticity and neurodegenerative disorders. J Clin Invest. 2001;107(3):247-54.

[36] Choi JJ, Choi J, Kang CD, Chen X, Wu CF, Ko KH, et al. Hydrogen peroxide induces the death of astrocytes through the down-regulation of the constitutive nuclear factor-kappaB activity. Free Radic Res. 2007;41(5):555-62.

[37] Shang YC, Chong ZZ, Hou J, Maiese K. Wnt1, FoxO3a, and NF-kappaB oversee microglial integrity and activation during oxidant stress. Cell Signal. 2010;22(9):1317-29.

[38] Corder EH, Saunders AM, Strittmatter WJ, Schmechel DE, Gaskell PC, Small GW, et al. Gene dose of apolipoprotein E type 4 allele and the risk of Alzheimer's disease in late onset families. Science. 1993;261(5123):921-3.

[39] Strittmatter WJ, Roses AD. Apolipoprotein E and Alzheimer disease. Proc Natl Acad Sci U S A. 1995;92(11):4725-7.

[40] Nickerson DA, Taylor SL, Fullerton SM, Weiss KM, Clark AG, Stengard JH, et al. Sequence diversity and large-scale typing of SNPs in the human apolipoprotein E gene. Genome Res. 2000;10(10):1532-45.

[41] Singh PP, Singh M, Mastana SS. APOE distribution in world populations with new data from India and the UK. Ann Hum Biol. 33(3):279-308.
[42] Jones L, Harold D, Williams J. Genetic evidence for the involvement of lipid metabolism in Alzheimer's disease. Biochim Biophys Acta. 2010;1801(8):754-61.

[43] Packard CJ, Westendorp RG, Stott DJ, Caslake MJ, Murray HM, Shepherd J, et al. Association between apolipoprotein E4 and cognitive decline in elderly adults. J Am Geriatr Soc. 2007;55(11):1777-85.

[44] Hayden KM, Zandi PP, West NA, Tschanz JT, Norton MC, Corcoran C, et al. Effects of family history and apolipoprotein E epsilon4 status on cognitive decline in the absence of Alzheimer dementia: the Cache County Study. Arch Neurol. 2009;66(11):1378-83.

[45] Whitehair DC, Sherzai A, Emond J, Raman R, Aisen PS, Petersen RC, et al. Influence of apolipoprotein E varepsilon4 on rates of cognitive and functional decline in mild cognitive impairment. Alzheimers Dement. 2010;6(5):412-9.

[46] Grootendorst J, de Kloet ER, Dalm S, Oitzl MS. Reversal of cognitive deficit of apolipoprotein $\mathrm{E}$ knockout mice after repeated exposure to a common environmental experience. Neuroscience. 2001;108(2):237-47.

[47] Oitzl MS, Mulder M, Lucassen PJ, Havekes LM, Grootendorst J, de Kloet ER. Severe learning deficits in apolipoprotein E-knockout mice in a water maze task. Brain Res. 1997;752(1-2):189-96.

[48] Raber J, Wong D, Yu GQ, Buttini M, Mahley RW, Pitas RE, et al. Apolipoprotein E and cognitive performance. Nature. 2000;404(6776):352-4.

[49] Bu G. Apolipoprotein E and its receptors in Alzheimer's disease: pathways, pathogenesis and therapy. Nat Rev Neurosci. 2009;10(5):333-44.

[50] Minihane AM, Jofre-Monseny L, Olano-Martin E, Rimbach G. ApoE genotype, cardiovascular risk and responsiveness to dietary fat manipulation. Proc Nutr Soc. 2007;66(2):183-97.

[51] Kim J, Basak JM, Holtzman DM. The role of apolipoprotein E in Alzheimer's disease. Neuron. 2009;63(3):287-303.

[52] Szekely CA, Breitner JC, Fitzpatrick AL, Rea TD, Psaty BM, Kuller LH, et al. NSAID use and dementia risk in the Cardiovascular Health Study: Role of APOE and NSAID type. Neurology. 2008;70(1):17-24.

[53] Hayden KM, Zandi PP, Khachaturian AS, Szekely CA, Fotuhi $\mathrm{M}$, Norton MC, et al. Does NSAID use modify cognitive trajectories in the elderly? The Cache County study. Neurology. 2007;69(3):275-82.

[54] Barger SW, Harmon AD. Microglial activation by Alzheimer amyloid precursor protein and modulation by apolipoprotein E. Nature. 1997;388(6645):878-81.

[55] Guo L, LaDu MJ, Van Eldik LJ. A dual role for apolipoprotein e in neuroinflammation: Anti- and pro-inflammatory activity. J Mol Neurosci. 2004;23(3):205-12.

[56] Lynch JR, Tang W, Wang H, Vitek MP, Bennett ER, Sullivan PM, et al. APOE genotype and an ApoE-mimetic peptide modify the systemic and central nervous system inflammatory response. J Biol Chem. 2003;278(49):48529-33.

[57] Colton CA, Czapiga M, Snell-Callanan J, Chernyshev ON, Vitek MP. Apolipoprotein E acts to increase nitric oxide production in macrophages by stimulating arginine transport. Biochim Biophys Acta. 2001;1535(2):134-44.

[58] Colton CA, Needham LK, Brown C, Cook D, Rasheed $\mathrm{K}$, Burke JR, et al. APOE genotype-specific differences in 
human and mouse macrophage nitric oxide production. Journal of Neuroimmunology. 2004;147(1-2):62-7.

[59] Dietrich M, Hu Y, Block G, Olano E, Packer L, Morrow $\mathrm{JD}$, et al. Associations between apolipoprotein $\mathrm{E}$ genotype and circulating F2-isoprostane levels in humans. Lipids. 2005;40(4):329-34.

[60] Graeser AC, Boesch-Saadatmandi C, Lippmann J, Wagner AE, Huebbe P, Storm N, et al. Nrf2-dependent gene expression is affected by the proatherogenic apoE4 genotypestudies in targeted gene replacement mice. J Mol Med (Berl). 89(10):1027-35.

[61] Jofre-Monseny L, de Pascual-Teresa S, Plonka E, Huebbe $\mathrm{P}$, Boesch-Saadatmandi C, Minihane AM, et al. Differential effects of apolipoprotein E3 and E4 on markers of oxidative status in macrophages. Br J Nutr. 2007;97(5):864-71.

[62] Jofre-Monseny L, Loboda A, Wagner AE, Huebbe P, BoeschSaadatmandi C, Jozkowicz A, et al. Effects of apoE genotype on macrophage inflammation and heme oxygenase-1 expression. Biochem Biophys Res Commun. 2007;357(1):319-24.

[63] Vitek MP, Brown CM, Colton CA. APOE genotype-specific differences in the innate immune response. Neurobiol Aging. 2009;30(9):1350-60.

[64] Maezawa I, Nivison M, Montine KS, Maeda N, Montine TJ. Neurotoxicity from innate immune response is greatest with targeted replacement of E4 allele of apolipoprotein E gene and is mediated by microglial p38MAPK. FASEB J. 2006;20(6):797-9.

[65] Ji Y, Gong Y, Gan W, Beach T, Holtzman DM, Wisniewski T. Apolipoprotein E isoform-specific regulation of dendritic spine morphology in apolipoprotein $\mathrm{E}$ transgenic mice and Alzheimer's disease patients. Neuroscience. 2003;122(2): 305-15.

[66] Li G, Bien-Ly N, Andrews-Zwilling Y, Xu Q, Bernardo $\mathrm{A}$, Ring $\mathrm{K}$, et al. GABAergic interneuron dysfunction impairs hippocampal neurogenesis in adult apolipoprotein E4 knockin mice. Cell Stem Cell. 2009;5(6):634-45.

[67] Muller W, Meske V, Berlin K, Scharnagl H, Marz W, Ohm TG. Apolipoprotein $\mathrm{E}$ isoforms increase intracellular $\mathrm{Ca} 2+$ differentially through a omega-agatoxin IVa-sensitive $\mathrm{Ca} 2+-$ channel. Brain Pathol. 1998;8(4):641-53.

[68] Cedazo-Minguez A, Wiehager B, Winblad B, Huttinger M, Cowburn RF. Effects of apolipoprotein E (apoE) isoforms, beta-amyloid (Abeta) and apoE/Abeta complexes on protein kinase $\mathrm{C}$-alpha (PKC-alpha) translocation and amyloid precursor protein (APP) processing in human SHSY5Y neuroblastoma cells and fibroblasts. Neurochem Int. 2001;38(7):615-25.

[69] Cedazo-Minguez A, Popescu BO, Blanco-Millan JM, Akterin S, Pei JJ, Winblad B, et al. Apolipoprotein E and betaamyloid (1-42) regulation of glycogen synthase kinase-3beta. J Neurochem. 2003;87(5):1152-64.

[70] Hoe HS, Harris DC, Rebeck GW. Multiple pathways of apolipoprotein E signaling in primary neurons. J Neurochem. 2005;93(1):145-55.

[71] Ohkubo N, Mitsuda N, Tamatani M, Yamaguchi A, Lee YD, Ogihara T, et al. Apolipoprotein E4 stimulates cAMP response element-binding protein transcriptional activity through the extracellular signal-regulated kinase pathway. J Biol Chem. 2001;276(5):3046-53.
[72] Ophir G, Amariglio N, Jacob-Hirsch J, Elkon R, Rechavi G, Michaelson DM. Apolipoprotein E4 enhances brain inflammation by modulation of the NF-kappaB signaling cascade. Neurobiol Dis. 2005;20(3):709-18.

[73] Maezawa I, Maeda N, Montine TJ, Montine KS. Apolipoprotein E-specific innate immune response in astrocytes from targeted replacement mice. J Neuroinflammation. 2006;3:10.

[74] Legos JJ, Tuma RF, Barone FC. Pharmacological interventions for stroke: failures and future. Expert Opin Investig Drugs. 2002;11(5):603-14.

[75] Narayan RK, Michel ME, Ansell B, Baethmann A, Biegon A, Bracken MB, et al. Clinical trials in head injury. J Neurotrauma. 2002;19(5):503-57.

[76] Joseph JA, Shukitt-Hale B, Denisova NA, Bielinski D, Martin A, McEwen JJ, et al. Reversals of age-related declines in neuronal signal transduction, cognitive, and motor behavioral deficits with blueberry, spinach, or strawberry dietary supplementation. Journal of Neuroscience. 1999;19(18):8114-21.

[77] Gomez-Pinilla F. Brain foods: the effects of nutrients on brain function. Nat Rev Neurosci. 2008;9(7):568-78.

[78] Parrott MD, Greenwood CE. Dietary influences on cognitive function with aging: from high-fat diets to healthful eating. Ann N Y Acad Sci. 2007 1114:389-97.

[79] Beking K, Vieira A. Flavonoid intake and disability-adjusted life years due to Alzheimer's and related dementias: A population-based study involving twenty-three developed countries. Public Health Nutr. 2011;13(9):1403-9.

[80] Letenneur L, Proust-Lima C, Le Gouge A, Dartigues JF, Barberger-Gateau P. Flavonoid intake and cognitive decline over a 10-year period. Am J Epidemiol. 2007;165(12):136471.

[81] Chan YC, Hosoda K, Tsai CJ, Yamamoto S, Wang MF. Favorable effects of tea on reducing the cognitive deficits and brain morphological changes in senescence-accelerated mice. J Nutr Sci Vitaminol (Tokyo). 2006;52(4):266-73.

[82] Haque AM, Hashimoto M, Katakura M, Tanabe Y, Hara Y, Shido O. Long-term administration of green tea catechins improves spatial cognition learning ability in rats. J Nutr. 2006;136(4):1043-7.

[83] Kaur T, Pathak CM, Pandhi P, Khanduja KL. Effects of green tea extract on learning, memory, behavior and acetylcholinesterase activity in young and old male rats. Brain Cogn. 2008;67(1):25-30.

[84] Kuriyama S, Hozawa A, Ohmori K, Shimazu T, Matsui T, Ebihara $\mathrm{S}$, et al. Green tea consumption and cognitive function: a cross-sectional study from the Tsurugaya Project 1. Am J Clin Nutr. 2006;83(2):355-61.

[85] Unno K, Takabayashi F, Yoshida H, Choba D, Fukutomi $\mathrm{R}$, Kikunaga N, et al. Daily consumption of green tea catechin delays memory regression in aged mice. Biogerontology. 2007:8(2):89-95.

[86] Oliveira DR, Sanada PF, Saragossa Filho AC, Innocenti LR, Oler G, Cerutti JM, et al. Neuromodulatory property of standardized extract Ginkgo biloba L. (EGb 761) on memory: Behavioral and molecular evidence. Brain Res. 2009; 1269:68-89.

[87] Shif O, Gillette K, Damkaoutis CM, Carrano C, Robbins SJ, Hoffman JR. Effects of Ginkgo biloba administered after spatial learning on water maze and radial arm maze 
performance in young adult rats. Pharmacol Biochem Behav. 2006;84(1):17-25.

[88] Fisher ND, Sorond FA, Hollenberg NK. Cocoa flavanols and brain perfusion. J Cardiovasc Pharmacol. 2006;47 Suppl 2:S210-4.

[89] Francis ST, Head K, Morris PG, Macdonald IA. The effect of flavanol-rich cocoa on the fMRI response to a cognitive task in healthy young people. J Cardiovasc Pharmacol. 2006;47 Suppl 2:S215-20.

[90] Dinges DF. Cocoa flavanols, cerebral blood flow, cognition, and health: Going forward. J Cardiovasc Pharmacol. 2006;47 Suppl 2:S221-3.

[91] Shukitt-Hale B, Lau FC, Carey AN, Galli RL, Spangler EL, Ingram DK, et al. Blueberry polyphenols attenuate kainic acid-induced decrements in cognition and alter inflammatory gene expression in rat hippocampus. Nutr Neurosci. 2008;11(4):172-82.

[92] Casadesus G, Shukitt-Hale B, Stellwagen HM, Zhu X, Lee HG, Smith MA, et al. Modulation of hippocampal plasticity and cognitive behavior by short-term blueberry supplementation in aged rats. Nutritional Neuroscience. 2004;7(5-6):309-16.

[93] Williams CM, El Mohsen MA, Vauzour D, Rendeiro C, Butler LT, Ellis JA, et al. Blueberry-induced changes in spatial working memory correlate with changes in hippocampal CREB phosphorylation and brain-derived neurotrophic factor (BDNF) levels. Free radical biology \& medicine. 2008;45(3):295-305.

[94] Krikorian R, Shidler MD, Nash TA, Kalt W, VinqvistTymchuk MR, Shukitt-Hale B, et al. Blueberry supplementation improves memory in older adults. J Agric Food Chem. 2010;58(7):3996-4000.

[95] Bastianetto S, Zheng WH, Quirion R. The Ginkgo biloba extract (EGb 761) protects and rescues hippocampal cells against nitric oxide-induced toxicity: involvement of its flavonoid constituents and protein kinase C. J Neurochem. 2000;74(6):2268-77.

[96] Luo Y, Smith JV, Paramasivam V, Burdick A, Curry KJ, Buford JP, et al. Inhibition of amyloid-beta aggregation and caspase-3 activation by the Ginkgo biloba extract EGb761. Proc Natl Acad Sci U S A. 2002;99(19):12197-202.

[97] van Praag H, Lucero MJ, Yeo GW, Stecker K, Heivand N, Zhao C, et al. Plant-derived flavanol (-)epicatechin enhances angiogenesis and retention of spatial memory in mice. J Neurosci. 2007;27(22):5869-78.

[98] Gage FH. Mammalian neural stem cells. Science. 2000; 287(5457):1433-8.

[99] Williams RJ, Spencer JP, Rice-Evans C. Flavonoids: antioxidants or signalling molecules? Free Radic Biol Med. 2004;36(7):838-49.

[100] Schroeter H, Bahia P, Spencer JP, Sheppard O, Rattray M, Cadenas E, et al. (-) Epicatechin stimulates ERK-dependent cyclic AMP response element activity and up-regulates GluR2 in cortical neurons. J Neurochem. 2007;101(6):1596606.

[101] Spencer JP. Flavonoids: Modulators of brain function? Br J Nutr. 2008;99 E Suppl 1:ES60-77.

[102] Li Q, Zhao HF, Zhang ZF, Liu ZG, Pei XR, Wang JB, et al. Long-term administration of green tea catechins prevents age-related spatial learning and memory decline in $\mathrm{C} 57 \mathrm{BL} / 6 \mathrm{~J}$ mice by regulating hippocampal cyclic amp-response element binding protein signaling cascade. Neuroscience. 2009;159(4):1208-15.

[103] Li Q, Zhao HF, Zhang ZF, Liu ZG, Pei XR, Wang JB, et al. Long-term green tea catechin administration prevents spatial learning and memory impairment in senescence-accelerated mouse prone- 8 mice by decreasing Abeta1-42 oligomers and upregulating synaptic plasticity-related proteins in the hippocampus. Neuroscience. 2009;163(3):741-9.

[104] Andres-Lacueva C, Shukitt-Hale B, Galli RL, Jauregui O, Lamuela-Raventos RM, Joseph JA. Anthocyanins in aged blueberry-fed rats are found centrally and may enhance memory. Nutr Neurosci. 2005;8(2):111-20.

[105] Joseph JA, Denisova NA, Arendash G, Gordon M, Diamond D, Shukitt-Hale B, et al. Blueberry supplementation enhances signaling and prevents behavioral deficits in an Alzheimer disease model. Nutr Neurosci. 2003;6(3):153-62.

[106] Joseph JA, Shukitt-Hale B, Denisova NA, Prior RL, Cao G, Martin A, et al. Long-term dietary strawberry, spinach, or vitamin $\mathrm{E}$ supplementation retards the onset of agerelated neuronal signal-transduction and cognitive behavioral deficits. J Neurosci. 1998;18(19):8047-55.

[107] Aberg MA, Aberg ND, Hedbacker H, Oscarsson J, Eriksson PS. Peripheral infusion of IGF-I selectively induces neurogenesis in the adult rat hippocampus. J Neurosci. 2000; 20(8):2896-903.

[108] Moore AH, O'Banion MK. Neuroinflammation and antiinflammatory therapy for Alzheimer's disease. Adv Drug Deliv Rev. 2002;54(12):1627-56.

[109] González-Gallego J, García-Mediavilla MV, SánchezCampos S, Tuñón MJ. Fruit polyphenols, immunity and inflammation. British Journal of Nutrition. 2010;104 SupplementS3:S15-27.

[110] Spencer JP, Vafeiadou K, Williams RJ, Vauzour D. Neuroinflammation: Modulation by flavonoids and mechanisms of action. Mol Aspects Med. 2012;33(1):83-97.

[111] Vafeiadou K, Vauzour D, Lee HY, Rodriguez-Mateos A, Williams RJ, Spencer JP. The citrus flavanone naringenin inhibits inflammatory signalling in glial cells and protects against neuroinflammatory injury. Arch Biochem Biophys. 2009;484(1):100-9.

[112] Lau FC, Bielinski DF, Joseph JA. Inhibitory effects of blueberry extract on the production of inflammatory mediators in lipopolysaccharide-activated BV2 microglia. J Neurosci Res. 2007;85(5):1010-7.

[113] Chen JC, Ho FM, Pei-Dawn Lee C, Chen CP, Jeng KC, Hsu $\mathrm{HB}$, et al. Inhibition of iNOS gene expression by quercetin is mediated by the inhibition of IkappaB kinase, nuclear factor-kappa B and STAT1, and depends on heme oxygenase1 induction in mouse BV-2 microglia. Eur $\mathrm{J}$ Pharmacol. 2005;521(1-3):9-20.

[114] Lee H, Kim YO, Kim H, Kim SY, Noh HS, Kang SS, et al. Flavonoid wogonin from medicinal herb is neuroprotective by inhibiting inflammatory activation of microglia. FASEB J. 2003;17(13):1943-4.

[115] Li R, Huang YG, Fang D, Le WD. (-)-Epigallocatechin gallate inhibits lipopolysaccharide-induced microglial activation and protects against inflammation-mediated 
dopaminergic neuronal injury. J Neurosci Res. 2004;78(5): 72331.

[116] Bhat NR, Zhang P, Lee JC, Hogan EL. Extracellular signal-regulated kinase and p38 subgroups of mitogenactivated protein kinases regulate inducible nitric oxide synthase and tumor necrosis factor-alpha gene expression in endotoxin-stimulated primary glial cultures. J Neurosci. 1998;18(5):1633-41.

[117] Leonardo CC, Dore S. Dietary flavonoids are neuroprotective through Nrf2-coordinated induction of endogenous cytoprotective proteins. Nutr Neurosci. 2011;14(5):226-36.

[118] Zheng LT, Ock J, Kwon BM, Suk K. Suppressive effects of flavonoid fisetin on lipopolysaccharide-induced microglial activation and neurotoxicity. Int Immunopharmacol. 2008;8(3):484-94.

[119] Williams RJ, Spencer JP. Flavonoids, cognition, and dementia: Actions, mechanisms, and potential therapeutic utility for Alzheimer disease. Free Radic Biol Med. 2012;52(1): 35-45.

[120] Barberger-Gateau P, Raffaitin C, Letenneur L, Berr C, Tzourio C, Dartigues JF, et al. Dietary patterns and risk of dementia: the Three-City cohort study. Neurology. 2007; 69(20):1921-30.

[121] Fedorova I, Salem N Jr. Omega-3 fatty acids and rodent behavior. Prostaglandins Leukot Essent Fatty Acids. 2006;75(4-5):271-89.

[122] Tully AM, Roche HM, Doyle R, Fallon C, Bruce I, Lawlor $\mathrm{B}$, et al. Low serum cholesteryl ester-docosahexaenoic acid levels in Alzheimer's disease: A case-control study. Br J Nutr. 2003;89(4):483-9.

[123] Kesse-Guyot E, Peneau S, Ferry M, Jeandel C, Hercberg S, Galan P. Thirteen-year prospective study between fish consumption, long-chain n-3 fatty acids intakes and cognitive function. J Nutr Health Aging. 15(2):115-20.

[124] Schaefer EJ, Bongard V, Beiser AS, Lamon-Fava S, Robins $\mathrm{SJ}, \mathrm{Au} \mathrm{R}$, et al. Plasma phosphatidylcholine docosahexaenoic acid content and risk of dementia and Alzheimer disease: the Framingham Heart Study. Arch Neurol. 2006;63(11):154550.

[125] Freund-Levi Y, Eriksdotter-Jonhagen M, Cederholm T, Basun H, Faxen-Irving G, Garlind A, et al. Omega-3 fatty acid treatment in 174 patients with mild to moderate Alzheimer disease: OmegAD study: a randomized double-blind trial. Arch Neurol. 2006;63(10):1402-8.

[126] Yurko-Mauro K, McCarthy D, Rom D, Nelson EB, Ryan AS, Blackwell A, et al. Beneficial effects of docosahexaenoic acid on cognition in age-related cognitive decline. Alzheimers Dement. 6(6):456-64

[127] Moriguchi T, Salem N Jr. Recovery of brain docosahexaenoate leads to recovery of spatial task performance. $\mathrm{J}$ Neurochem. 2003;87(2):297-309.

[128] He C, Qu X, Cui L, Wang J, Kang JX. Improved spatial learning performance of fat-1 mice is associated with enhanced neurogenesis and neuritogenesis by docosahexaenoic acid Proc Natl Acad Sci U S A. 2009;106(27):11370-5.

[129] Moriguchi T, Greiner RS, Salem N Jr. Behavioral deficits associated with dietary induction of decreased brain docosahexaenoic acid concentration. J Neurochem. 2000;75(6):2563-73
[130] Su HM. Mechanisms of $\mathrm{n}-3$ fatty acid-mediated development and maintenance of learning memory performance. J Nutr Biochem. 2010;21(5):364-73.

[131] Orr SK, Bazinet RP. The emerging role of docosahexaenoic acid in neuroinflammation. Curr Opin Investig Drugs. 2008;9(7):735-43.

[132] Faghiri Z, Bazan NG. PI3K/Akt and mTOR/p70S6K pathways mediate neuroprotectin D1-induced retinal pigment epithelial cell survival during oxidative stress-induced apoptosis. Exp Eye Res. 2010;90(6):718-25.

[133] Akbar M, Calderon F, Wen Z, Kim HY. Docosahexaenoic acid: a positive modulator of Akt signaling in neuronal survival. Proc Natl Acad Sci U S A. 2005;102(31):10858-63.

[134] Musiek ES, Brooks JD, Joo M, Brunoldi E, Porta A, Zanoni $\mathrm{G}$, et al. Electrophilic cyclopentenone neuroprostanes are anti-inflammatory mediators formed from the peroxidation of the omega-3 polyunsaturated fatty acid docosahexaenoic acid. J Biol Chem. 2008;283(29):19927-35.

[135] Bazan NG, Molina MF, Gordon WC. Docosahexaenoic acid signalolipidomics in nutrition: significance in aging, neuroinflammation, macular degeneration, Alzheimer's, and other neurodegenerative diseases. Annu Rev Nutr. 2011;31:32151.

[136] Marcheselli VL, Hong S, Lukiw WJ, Tian XH, Gronert $\mathrm{K}$, Musto A, et al. Novel docosanoids inhibit brain ischemia-reperfusion-mediated leukocyte infiltration and pro-inflammatory gene expression. J Biol Chem. 2003; 278(44):43807-17.

[137] Jang JH, Surh YJ. Beta-amyloid-induced apoptosis is associated with cyclooxygenase-2 up-regulation via the mitogen-activated protein kinase-NF-kappaB signaling pathway. Free Radic Biol Med. 2005;38(12):1604-13.

[138] Lukiw WJ, Cui JG, Marcheselli VL, Bodker M, Botkjaer A and Gotlinger K, et al. A role for docosahexaenoic acid-derived neuroprotectin D1 in neural cell survival and Alzheimer disease. J Clin Invest. 2005;115(10):2774-83.

[139] Quinn JF, Raman R, Thomas RG, Yurko-Mauro K, Nelson EB, Van Dyck C, et al. Docosahexaenoic acid supplementation and cognitive decline in Alzheimer disease: A randomized trial. JAMA. 2010;304(17):1903-11.

[140] Huang TL, Zandi PP, Tucker KL, Fitzpatrick AL, Kuller LH, Fried LP, et al. Benefits of fatty fish on dementia risk are stronger for those without APOE epsilon4. Neurology. 2005;65(9):1409-14

[141] Whalley LJ, Deary IJ, Starr JM, Wahle KW, Rance KA, Bourne VJ, et al. n-3 Fatty acid erythrocyte membrane content, APOE varepsilon4, and cognitive variation: an observational follow-up study in late adulthood. Am J Clin Nutr. 2008;87(2):449-54.

[142] Luchsinger JA, Tang MX, Shea S, Mayeux R. Caloric intake and the risk of Alzheimer disease. Arch Neurol. 2002;59(8):1258-63.

[143] Bourre JM. Roles of unsaturated fatty acids (especially omega- 3 fatty acids) in the brain at various ages and during ageing. J Nutr Health Aging. 2004;8(3):163-74.

[144] Sloane PD, Zimmerman S, Suchindran C, Reed P, Wang L, Boustani M, et al. The public health impact of Alzheimer's disease, 2000-2050: potential implication of treatment advances. Annu Rev Public Health. 2002;23:213-31. 